\title{
Peschiera australis (Muell. Arg.) Miers SOBRE O EDEMA PRODUZIDO POR CARRAGENINA, NA REGIĀO PLANTAR DE RATOS WISTAR*
}

Doris Medianeira Lazzaroto, Maria Edite Haesbaert

Curso de Medicina. Centro de Ciēncias da Saūde. UFSM. Santa Maria, RS. Sônia Maria Eisinger

Departamento de Biologia. Centro de Ciēncias Natura is e Exatas.UFSM. Santa Maria, RS.

Ana ilaria Chagas

Departamento de Fisiologia. Centro de Ciências da Saúde. UFSM. Santa Maria, RS.

\section{RESUMO}

A Peschiera australis (Muel1. Arg.) Miers é um arbusto do sul do Brasil que no uso popular atua contra envenenamento de ser pentes. Desta maneira pretendeu-se analisar a influência da mesma na formação do edema, uma vez que este è um sinal grave que ocorre por intoxicação de venenos. Utilizamos ratos Wistar divididos em quatro grupos e anestesiados pelo Pentobarbital.

o grupo controle recebeu carraginina na planta da pata e, em intervalos de 15 minutos durante 4 horas, foi avaliada a evolu ção do edema no plestimōgrafo. 0 segundo grupo recebeu o tratamento idêntico ao anterior, mas associado à administração de extrato aquo so via oral de Peschiera australis. No terceiro grupo o tratamento foi idéntico ao anterior, exceto a via de administração do extrato de Peschiera australis, que neste caso é intraperitoneal e no quar to grupo foi usada a via endovenosa,que apresentou a diminuição do edema mas não o aboliu.

\section{SUMMARY}

LAZZAROTO, D.M.; HAESBAERT, M.E.; EISINGER, S.M. and CHAGAS, A.M., Peschiera australis (Muell. Arg.) Miers in edema evolution in Wistar rats. Ciência e Natura, $8: 81-86$.

The Peschiera australis (Muell. Arg.) Miers is a plant from Southern Brasil that in popular use acts against snake poison because of that, we wanted to absorve the influence of Pescheria australis in edema evolution, since it is a strong sign of intoxication. We used Wistar rats divided into four groups. Pentobarbital $(40 \mathrm{mg} / \mathrm{kg}$ bady weight) was used as anestesic. The control group received carragenina the bottom of their feet and in 15 minutes intervals for hours the edema evolution wasy observed in plestesmograph.

The second group received the same treatment but the used

\footnotetext{
* Trabalho Financiado pelo FIPE/UFSM
} 
substance was Peschiera australis extract by oral route. In a third group extract was given by intraperitoneal route and in a fourth, by endovenous route. The given extract endovenous route was the only one that showed results in edema, provoking its involution, but not total disappearance.

INTRODUÇÃO

A Peschiera australis (Muell. Arg.) Miers è um arbusto na tivo do sul do Brasil, nordeste da Argentina, Uruguai e Paraguai ( 3 e 6), sendo conhecida popularmente na Argentina como "Palo vivora", Zapiranguy-guazū e no sul do Brasil por Jasmin catavento ou Jasmin pipoca. Este arbusto possui de 4 a 8 metros de altura com tronco de aproximadamente 20 centỉmetros de diámetro, liso ou levemente ru goso de ramos nodosos e ramificações dicotōmicas. As folhas são sim ples de coloração verde clara, 5 a $7 \mathrm{~mm}$ de comprimento e persisten tes em pares lanceolados $(3,9,10$ e 11). Fig. 1. Nas regiões onde esta planta è nativa ela é utilizada para atenuar os sintomas de envenenamento de serpentes (3).

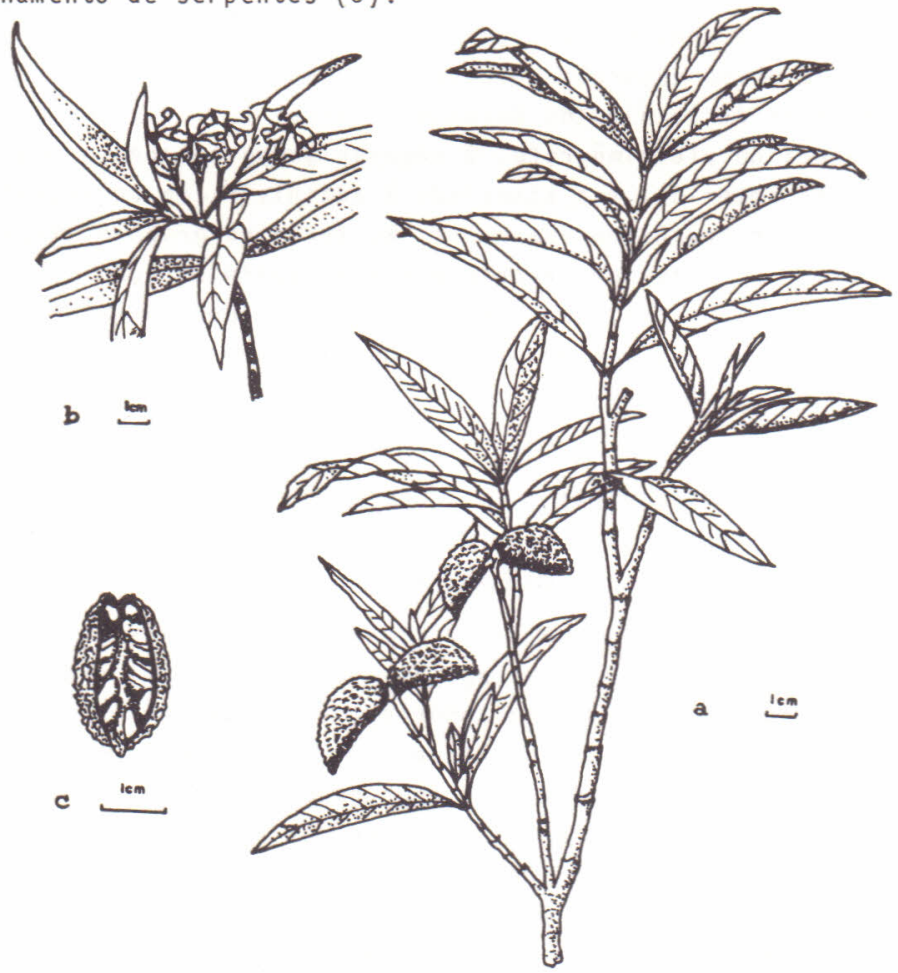

Figura 1 - Peschiera australis (Muell. Arg.) Miers: a, Ramo com fru tos: b. fruto maduro deiscente. 
Sabe-se que entre todos os venenos, os de serpentes são os mais complexos e exercem efeito tóxico e letal sobre o sangue, sistema cardiovascular, respiratörio e nervoso. Podem ser classifi cados em vārios grupos fundamentais de acordo com o principal efe to patofisiológico. As Viperidae e Crotalidae produzem, além de efeitos sistemäticos e letais, efeitos locais constituindo hemorra gia, necrose e edema assim como marcada alteração na coagulação san güinea (4). O veneno da jararaca produz 1 iberação de cininas hipo tensoras no rato (18 e 19). FELDBERG e KELLAWAY (8) mostraram que o veneno de serpentes produz liberação de Histamina pela perfusão de pulmão de cobaios e gatos.

Os venenos de ofỉdios possuem ação proteolỉtica que é res ponsāvel por dor, edema firme, rubor, bol has hemorrāgicas ou não que podem ser seguidas de necrose que atinge a pele, müsculos e tendões. As enzimas proteoliticas podem, pela agressão de proteînas, induzir à liberação de substāncias vasoativas, tais como bradicinina e a histamina, que nos casos graves por mecanismo auto-farmacológico, po dem levar ao choque. (15).

Experimentos em ratos têm mostrado que injeções de agen tes liberadores de histamina e serotomina como ë o caso de veneno de serpentes, aumentam a permeabilidade vascular, provocando um es travasamento de līquido e proteỉna plasmātica para o espaço extravascular e, consequlentemente, a formação de edemas no local da inje ção $(1,2,11,16$ e 17$)$.

0 edema na pata do rato pela injeção de carragenina é um modelo utilizado na investigação da ação de substāncias ou fārmaco com propriedades anti-inflamatōrias pelo fato de ser possīvel quan tificar pela medida da pata, ao nīvel da articulação tỉbio-tārsica, pelo mētodo do plestimōgrafo $(1,4,13$ e 20), a variabilidade de um edema (Fig. 2).

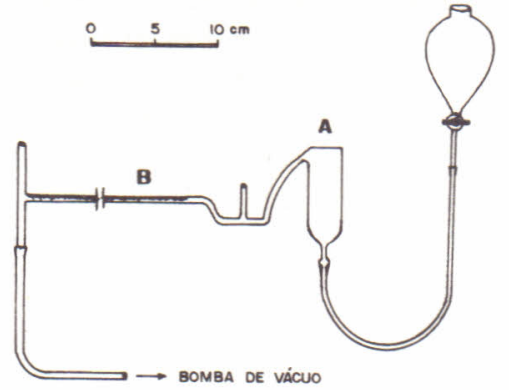

Figura 2 - Plestimōgrafo para medida de volume de pata de rato.

$A=$ Câmara para imersão da pata.

$B=$ Microbureta graduada. 
Com a finalidade de avaliar o efeito do extrato aquoso por diferentes vias de administração da Peschiera austrazis sobre 0 edema plantar de rato produzido pela carragenina, foi efetuado 0 presente estudo.

MATERIAL E METODO

No presente trabalho, utilizou-se 82 ratos Wistar machos, adultos que foram divididos em 4 grupos. Os animais foram mantidos em gaiolas de madeira no biotério do Departamento de Fisiologia com àgua e alimento à vontade.

0 primeiro grupo, controle, recebeu injeção sub-cutâneade $0,1 \mathrm{ml}$ de carragenina $\bar{a} 2 \%$ ao nīvel da articulação metacarpiana, com a finalidade de induzir o edema segundo a tēcnica de Winter et ali (20). A evolução do edema induzido foi avaliada de 15 em 15 minutos durante 4 horas.

No segundo grupo, apōs a produção do edema conforme o gru po controle, os animais receberam $0,5 \mathrm{ml}$ de extrato aquoso de Pes chiera australis na concentração de $10 \%$, pela via endovenosa e para este fim utilizou-se a veia peniana. Após 10 minutos as medições con tinuaram a ser efetivadas em intervalos de 15 minutos durante 4 ho ras.

No terceiro e quarto grupo o procedimento foi idêntico so mente variando a via de administração que no primeiro caso foi avia oral, e no segundo caso a via intraperitoneal.

Antes de efetuar os experimentos em todos os 4 grupos, os animais foram anestesiados com pentabarbital södico com a finalida de de eliminar a dor e obtenção de melhores resultados atravēs das vārias medidas efetivadas.

As medições foram efetuadas em todos os animais, em cada 15 minutos, durante 240 minutos, e para isto, utilizou-se o plesti mōgrafo de acordo com winter et alii (20). Fig. 2.

Em todos os resultados foram ef etuados testes estatisticos "T" de Student, segundo as especificações de DIXON e MASSEY (7).

Preparo do Extrato: A planta foi coletada no Campus da Universidade Federal de Santa Maria, classificada posteriormente se ca em lugar ventilado a temperatura ambiente durante 20 dias. Colo cou-se 100 gramas de folhas secas trituradas, em um 1 itro de ägua que permaneceu em infusão por 24 horas a $10^{\circ} \mathrm{C}$. Após efetuou-se a filtração, liofilização e o extrato foi mantido a $4{ }^{0} \mathrm{C}$.

RESULTADOS E DISCUSSÃO

A injeção de carragenina pela via subcutânea produziu em 3 horas, um aumento gradativo de volume máximo das patas dos ratos no grupo controle. 
Nos animais que receberam o extrato aquoso de Peschiera australis pela via oral e intraperitoneal observou-se que não houve alteração significativa. (Fig. 3). Talvez não tenha ocorrido absor ção completa porque, como ē sabido, a absorção pela mucosa estoma cal e/ou digestiva dependem de alguns fatores como o pka, a solubi lidade da substāncia, a lipossolubilidade, o tamanho das moléculas, etc. (5).

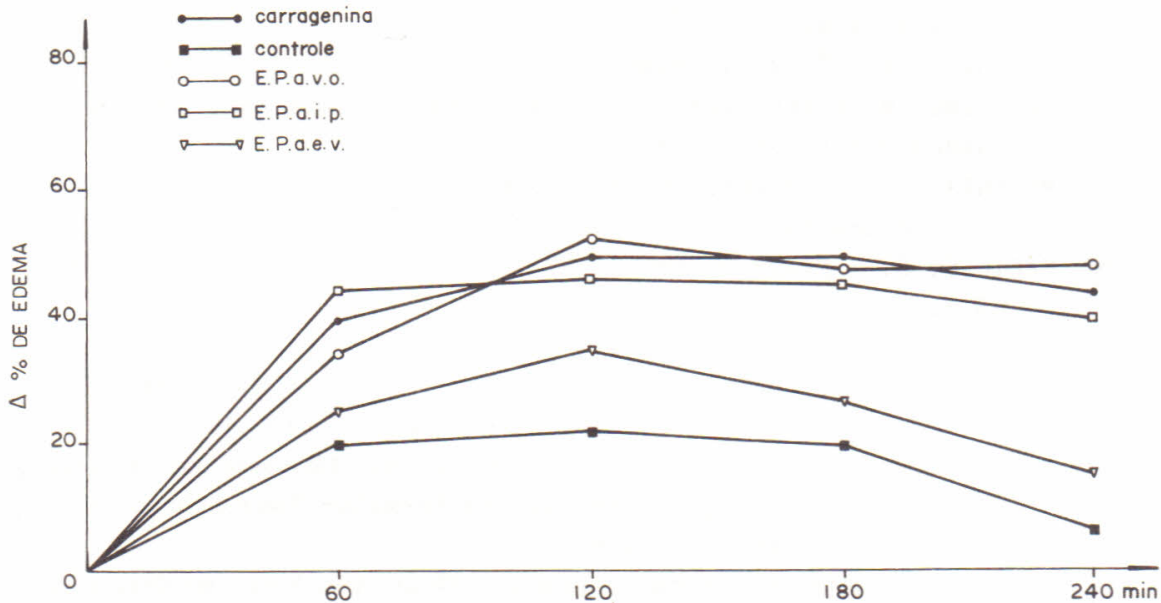

Figura 3 - Representação gräfica em diferença de percentual $\cdot(\%)$ do edema produzido pela administração de carragenina e uti 1 ização de extrato aquoso de Peschiera australis (E.P.a.) pelas diferentes vias de administração (V.0. = via oral, $I . P .=$ intraperitoneal, e E.V. = via endovenosa.

Com relação aos animais tratados com Peschiera australis pela via endovenosa na dose de $0,5 \mathrm{ml}$ houve uma diminuição signif $\underline{j}$ cativa do edema de $25 \%$ apōs 150 minutos e permaneceu nestes nỉveis atè às 4 horas. Verifica-se que a atividade anti-inflamatōria da Peschiera australis ocorre somente quando administrada endovenosa mente. Talvez este efeito antiedematoso da Peschiera austrazis seja devido a via undovenosa não necessitar de absorção e a concentração ao nivel sanguíneo do extrato ser maior (5).

BIBLIOGRAF I A CITADA

1. ARMAN, G.G.V.; BEgANY, A.J.; MILLER, L.M. \& PLESS, H.H. - Some details of the inflamations caused bu jeast and carragenin. J.Pharmacol Exp., Ther., Baltimore 150(2):328-334, 1965.

2. AZEVEDO, A.C.P. - Serpentes Venenosas do Rio Grande do Sul. 3 ed. Pelotas, Sulina. 1966, $36 \mathrm{p}$.

3. BURKART, A. - Flora Ilustrada de Entre Rios. ParteV. Colecion 
Cientif Del Inta (Argentina) Tomo VI, 1979, 96 p.

4. BURN, J.H. - Pratical Pharmacology. Oxford. Blacwell Scientif Publication, 1952, $402 \mathrm{p}$.

5. CHAGAS, A.M.; MACHADO, E.K.; CATALDI, FOQ.R.; BOELTER, R.\& FRICK, W. - Fxrmacologia Geral. Sta. Maria, Editora UFSM, 1978, 62 p.

6. DECANDOLLE, A. - Taburnaemontanoidum. Prodom., Alemanha. 8:360$8,1944$.

7. DIXON, W.J. \& MASSEY, Jr.F.J. - Introduction To Statistical Analusis. 3a ed. WASHINGTON, Mac Graw Hill, 1975,501 p.

8. FEldberg, W. \& KELLANAY, C.H. - Release of Histamine. J.Physiol. London 90:257-262, 1937.

9. MARKGRAF, F. - Taburnae Montanoidum. Die Amerik Notizblatt Bot Gart. Alemanha. 14:(122):151-77, 1954.

10. MARTEVS, 0. - Flora do Brasiz 2 a ed. Porto Alegre, Sulina, 1960, $89 \mathrm{p}$.

11. MICHAELIS, B.A. \& RUSSEL, F. - Effects of Crotalus Venon on Intergrity of Capillary Va11. Toxicon, Oxford, 1:245-6, 1963.

12. MIERS, A. - South America. 2- ed. Chicago, Apocynac, 1978. 197 p.

13. NORTH, M.A. - Naloxone Reversal of Morphine Analgesie But Failures To After Reactivity To Pain In The Formalum Test.Life Sciences. 0xford $22(4): 295-302,1978$.

14. OYAMA, 0. - Effects of Snake Venous. 3a ed. Nova York. Mac Graw Hill Book Go. Inc. 1975, 503 p.

15. RAHNE, A.F. \& TORRES, J.B. - Produção De Veneno De Serpentes em Cativeiro. Rev.Bras. Saúde ocup., Rio de Janeiro 12(46):53-60, 1984.

16. ROCHA e SILVA, M.A. - A comprehensive theory of the mechanism of the histamine release. Anais A.Bras. Ciências, São Paulo, 31:77-82, 1959 .

17. ROCHA e SILVA, M.A.; BERALD, W.T. \& ROSENFELD, G. - Bradykinin a hipotensive and smook muscle stimulating factor released from plasma glubin by snake venons abd trypsin. Am.J.Phisiol, London, 156:261-78, 1949 .

18. ROTHSCHILD, A.M. - Mechanism of Histamine release by animal ve nons. Memb.Inst.Butantã, São Paulo, 33:467-71, 1966.

19. ROTHSCHILD, A.M. \& ALMEIDA, J.A. - Emprego de sulfato de celulo se e de Heparina para investigar a participação de Bradicini na no Efeito Letal do Veneno de Bothrops jararāca no rato. Rev.Bras.de Pesquisas Méd.Biológ, (Brasil) 2(3):163-66, 1969.

20. WINTER, C.A.; RISLEY, E.A. \& NUSS, G.W. - Carragenin induced edema in hind pain of the rat as an assay for antiinflamatory drugs. Proc.Soc.Exp.Biol. New York. 111:544-50, 1962.

Recebido em novembro, 1986; aceito em dezembro, 1986. 